\title{
Schiff Bazı Esaslı Destekli Sıvı Membranlar ile Sulu Çözeltiden Cu(II) İyonlarının Donnan Diyaliz Metodu ile Ayrılması
}

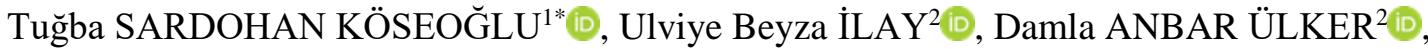 Gülden TEKİN ${ }^{2}$, Esengül KIR ${ }^{2}$ (D) Fatma KARIPCIN ${ }^{3}$}

\author{
${ }^{1}$ Isparta Uygulamalı Bilimler Üniversitesi, Teknoloji Fakültesi, Biyomedikal Mühendisliği Bölümü, Çünür \\ Kampüsü, 32260 Isparta, Türkiye \\ ${ }^{2}$ Süleyman Demirel Universitesi, Fen-Edebiyat Fakültesi, Kimya Bölümü, Çünür Kampüsü, 32260 Isparta, \\ Türkiye \\ ${ }^{3}$ Nevşehir Hacı Bektaş Veli Üniversitesi, Fen-Edebiyat Fakültesi, Kimya Bölümü, Nevsehir, \\ 50300, Türkiye
}

Geliş / Received: 27/02/2020, Kabul / Accepted: 20/08/2020

\begin{abstract}
Özet
$\mathrm{Bu}$ çalışmada, daha önceden sentezlenmiş olan 4-(4-\{4-[1-metil-3-oksobutilidenamino] fenil \} fenilimino)-2pentanon (BAA) Schiff bazı kullanılarak farklı destek tabakaları ve farklı çözücüler ile destekli sıvı membranlar hazırlanmıştır. Donnan diyaliz yöntemi ile sulu ortamda belli bir miktarı aşması durumunda zararlı olabilecek $\mathrm{Cu}$ (II) katyonunun seçimli olarak ayrılması ve taşınması özellikleri bu yeni hazırlanan membranlar kullanılarak incelenmiştir. $\mathrm{Bu}$ membranlar kullanılarak konsantrasyon etkisinin $\mathrm{Cu}(\mathrm{II})$ iyonunun taşınmasındaki etkisi incelenmiş ve $\mathrm{Cu}$ (II) için akı (J) değerleri hesaplanmıştır. $\mathrm{Cu}$ (II) metal iyonunun akısı, konsantrasyon artışı ile artmıştır. Farklı membranlarda farklı akı değerlerinin olması, membran yapılarının farklılı̆̆ ile açıklanmıştır. Hazırlanan bu yeni tip membranların karakterizasyon işlemleri SEM, AFM ve FTIR ile yapılmıştır. Hazırlanan membranların kalınlıkları da belirlenmiştir. Ayrıca, membranların potansiyel ölçüm deneyleri de incelenmiştir.
\end{abstract}

Anahtar Kelimeler: Schiff bazı, Destekli sıvı membran, Cu(II), Donnan diyaliz

Separation of $\mathrm{Cu}$ (II) ions from aqueous solution with Supported Liquid Membranes based Schiff Base by Donnan Dialysis Method

\begin{abstract}
Abctract
In this work, supported liquid membranes with different support layers and different solvents were prepared using the previously synthesized 4- (4- \{4- [1-methyl-3-oxobutylideneamino] phenyl $\}$ phenylimino) -2pentanone (BAA) Schiff base. The selective separation and transport properties of the $\mathrm{Cu}$ (II) cation, which may be harmful in case of exceeding a certain amount in the aqueous medium have been investigated using these new prepared membranes by the Donnan dialysis method. The effect of the concentration effect on the transport of the $\mathrm{Cu}$ (II) ion was investigated using these membranes and the flux (J) for $\mathrm{Cu}$ (II) were calculated. The flux of $\mathrm{Cu}(\mathrm{II})$ metal ion increased with an increase in concentration. The different fluxs in different membranes are explained by the difference of membrane structures. Characterization of these new prepared membranes was carried out by SEM, AFM and FTIR. The thicknesses of the prepared membranes were also determined. In addition, potential measurement experiments of membranes were also examined.
\end{abstract}

Keywords: $\mathrm{Cu}(\mathrm{II})$, Donnan dialysis, Schiff base, Supported Liquid Membrane

\section{Giriş}

Doğal sulardaki bakırın kimyasal tayini toksik özelliğinden ve sucul mikroorganizmalar tarafindan özümsenmesi sebebiyle önemli bir parametredir (Ndungu vd., 2005). Son y1llarda membran teknolojisi, kimyasal çöktürme, adsorpsiyon vb. diğer klasik analitik metotlara göre daha ekonomik olması ve uygulamadaki kolaylığı 
nedeniyle ayırma işlemlerinde oldukça fazla tercih edilmektedir. Membranlar özellikle sulardan istenmeyen iyonların uzaklaştırılması ve suların saflaştırılmasında kimya sanayi başta olmak üzere, eczacillk, petrol endüstrisi, hidrometalurji, elektrodiyaliz, çevre, gıda teknolojisi, genetik ve tekstil endüstrisi gibi alanlarda yoğun olarak kullanılmaktadır

Destekli sıvı membran (DSM), eser metal ayırma ve ön deriştirme aracı olarak ifade edilmektedir. DSM sistemleri iki su fazında çalışmaktadır. Birinci faz, analiti içeren kaynak besleme (donör) çözeltisi, ikincisi ise analitlerin içine alınıp tutulduğu alıcı çözeltisidir (Ndungu vd., 2005; Romero ve Jönsson, 2005). Destekli siv1 membranlar krom, bakır, çinko, alüminyum ve $\mathrm{Fe}(\mathrm{III})$ gibi farklı metallerin ekstraksiyon/ayırma çalışmaları için sıklıkla kullanılmaktadır (Parhi ve Sarangi, 2008).

Siv1 membran prosesleri, metal iyonları, zayıf asitler ve bazlar, hidrokarbonlar veya biyolojik olarak önemli bileşikler ve gaz karışımları gibi çeşitli türlerin konsantrasyonları ve seçici ayrılması için yeni ve etkili bir metot olarak son y1llarda hızla ilerlemektedir (Yang ve Fane, 1999). Modern teknolojide sıv1 membranlar sıv1 yüzey aktif membranlar ve polimer-destekli sıv1 membranlar olmak üzere iki gruba ayrılmaktadır. Sıvı yüzey membranlar, ultra-ince sıvı membran ve geniş arayüz alanı gibi avantajlara sahiptir. Fakat, yüzey aktif maddenin kullanımı reaksiyon hızının azaltılması, sulu fazların ya da emülsiyonlaşmanın içine yüzeyin dağılması gibi olumsuz olaylara neden olmaktadır. Diğer taraftan, DSM membranların pratik uygulamaları için DSM membranların spesifik yüzey alanının nispeten küçük olmas1, DSM boyunca difüzyon direncinin büyük olması gibi çözülmesi gereken bazı problemler de bulunmaktadır (Takahashi ve Takeuchi, 1985). DSM membranların geleneksel ayırma tekniklerine göre avantajları arasında düşük sermaye ve işletme maliyeti, düşük enerji ve ekstraktant maliyeti, yüksek konsantrasyon faktörleri ve katı membranlara kıyasla yüksek akış sayılabilmektedir. Bu avantajlardan dolayı DSM membranlar bakır, krom ve gümüş gibi farklı metallerin geri kazanılması için oldukça uygundur (Gherrou vd., 2002).

$\mathrm{Bu}$ çalışmada, daha önceden sentezlenmiş olan 4-(4-\{4-[1-metil-3oksobutilideneamino] fenil\} fenilimino)-2pentanon (BAA) bileşiği kullanılarak katyon değiştirici özelliğe sahip destekli sıv1 membranların hazırlanması amaçlanmıştır. Çalışmamızda membran hazırlanmasında kullandığımız Schiff bazının genel gösterimi Şekil 1'de verilmiştir. $\mathrm{BAA}$ bileşiği, literatürdeki hazırlama metodu modifiye edilerek sentezlenmiştir (Shauib vd., 2006). Membran destek tabakası olarak poliamit ve hidrofob PVDF (poliviniliden florür) destek tabakaları kullanılmıştır. Hazırlanan bu yeni tip membranların, spektroskopik (FTIR), morfolojik (SEM), (AFM) ve elektriksel (potansiyel) özelliklerinin incelenmesi çalışmaları da yapılmıştır. Karakterizasyon işlemleri tamamlanan membranlar ile $\mathrm{Cu}(\mathrm{II})$ iyonunun seçimli olarak ayrılması ve taşınması çalışmaları gerçekleştirilmiş̧tir. Sulu ortamlarda belirli konsantrasyon değerleri aşıldığında zararlı etkileri ortaya çıkan $\mathrm{Cu}(\mathrm{II})$ iyonunun giderimi çevre sağlı̆̆ı açısından oldukça önemlidir. $\mathrm{Bu}$ amaçla, membranlar kullanılarak sulu çözelti ortamından $\mathrm{Cu}(\mathrm{II})$ iyonlarının uzaklaştırılması Donnan Diyaliz yöntemi ile gerçekleştirilmiş ve deney 
öncesinde ve sonrasında iyonların ölçümleri

ICP-OES ile yapılmıştır.

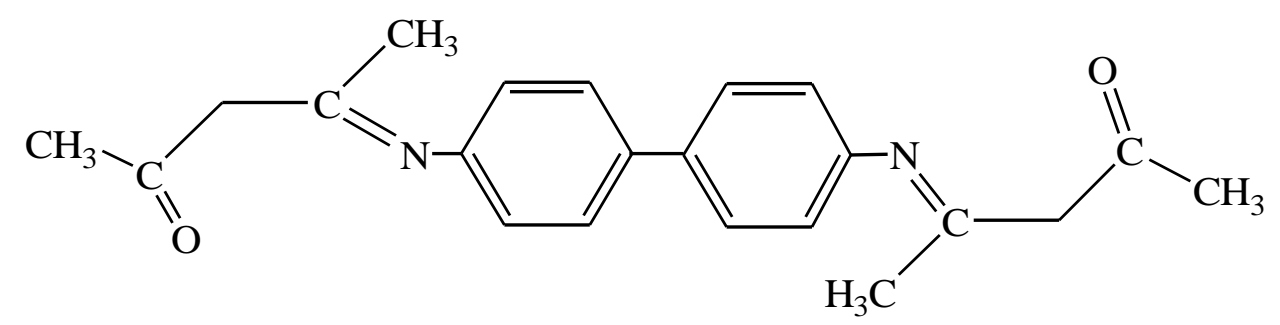

Şekil 1. 4-(4-\{4-[1-metil-3-oksobutilidenamino] fenil\} fenilimino)-2-pentanon (BAA)

\section{Materyal ve Metot}

\subsection{Kimyasallar}

Deneylerde kullanılan bütün kimyasallar analitik saflıktadır. Dimetilformamit (DMF), diklorametan (DCM), bakır(II) nitrat ve sodyum klorür Merck firmasından temin edilmiştir. Çalışmada, Millipore Milli-Q su arıtma sisteminden elde edilen saf su kullanılmıştır.

\subsection{Destekli Sivı Membranların Hazırlanması}

BAA-Poliamit membranın hazırlanmasında, yaklaşık $0,05 \mathrm{~g}$ BAA tartılmış ve $3 \mathrm{~mL}$ DMF'de çözülmüştür. Çözme işleminden sonra içinde poliamit destek tabakası bulunan bir petri kabına alınmıştır. Yaklaşık 24 saat oda sıcaklığında çözücüsü uzaklaştırılarak kuruması ve
BAA'nın poliamit destek tabakası üzerine tutturulması sağlanmıştır.

BAA-PVDF membranın hazırlanmasında, yaklaşık 0,05 g BAA tartılmış ve $3 \mathrm{~mL}$ DCM'de çözülmüş, çözme işleminden sonra içinde hidrofob PVDF destek tabakası bulunan bir petri kabına alınmıştır. Benzer şekilde, yaklaşık 24 saat oda sıcaklığında çözücüsü uzaklaştırılarak kuruması ve BAA'nın hidrofob PVDF destek tabakası üzerine tutturulması sağlanmıştır.

\subsection{Membran Destek Tabakası}

Çalışma kapsamında kullanılan destek tabakaları poliamit ve hidrofob PVDF destek tabakalarıdır. Hazırlanan membranların polimer içeriklerini bu destek tabakaları sağlamaktadır. Deneylerde kullanılan destek tabakalarının özellikleri Tablo 1'de verilmiştir.

Tablo 1. Çalışmada kullanılan destek tabakalarının özellikleri

\section{Destek tabakası}

\section{Gözenek Çapı Kalınlığı Çeşidi}

$(\mu \mathrm{m})$

$(\mu \mathrm{m})$

(Islanabilirlik)

Geçirgenlik 


\begin{tabular}{ccccc}
\hline PVDF & 0,22 & 110 & Hidrofobik & $\% 70$ \\
\hline Poliamit & 0,45 & 115 & Hidrofilik & - \\
\hline
\end{tabular}

\subsection{Membran kalınlıklarmın tayini}

Membran kalınlığ 1 Mitutoya CD-15CPX dijital mikrometre ile membranın farklı bölgelerinde ölçülmüştür (kenarlarda ve ortalarda). Ölçümlerden önce, membranlar kurutulmak üzere vakum altında bekletilmiş ve membranların kalınlıkları ölçülmüştür (Silva vd., 2004).

\subsection{Donnan diyaliz deneyleri}

Deneyler Teflon malzemeden yapılmış iki bölmeli donnan diyaliz ünitesinde gerçekleştirilmiş̧tir (Cengeloglu vd., 2001). Deney süresince alıcı çözeltiden belirli zaman aralıklarında (her 30 dakikada bir) örnek numuneleri alınmışı̧ı. Destekli sıvı membranlar boyunca taşınan $\mathrm{Cu}(\mathrm{II})$ iyonlarının miktarları ICP-OES (Perkin Emler 5300 DV model) ile ölçülmüştür. Bu metal iyonlarının miktarından akı $(J)$ değerleri hesaplanmıştır. Süreye karşılık taşınan metal mmol miktarları grafiğe geçirilmiştir. Tüm ölçümler $25^{\circ} \mathrm{C}$ 'de yapılmış ve her bir deney en az üç kez tekrar edilmiş̧ir. Sonuçlar $\% 95$ güven seviyesinde değerlendirilmiştir.

\subsection{Membran Potansiyeli}

Tablo 2. Çalışmada hazırlanan membranların kalınlık değerleri
Membran potansiyellerinin ölçüm deneyleri, $\mathrm{E}_{\mathrm{m}}$, donnan diyaliz hücresinde yapılmışıır. Potansiyel ölçümleri, $\mathrm{Ag} / \mathrm{AgCl}$ elektrotlar (Mettler Toledo Inlab Reference Pro) ve bir elektrometre (Fluke 87 III True Rms Multimeter) kullanılarak gerçekleştirilmiştir.

\subsection{Yüzey Karakterizasyonu}

Hazırlanan membranların yüzey karakterizasyonları, spektroskopik (FTIR), morfolojik (SEM, AFM) ve elektriksel (potansiyel) özelliklerinin incelenmesi ile aydınlatılmıştır. FTIR ölçümleri, Perkin Elmer-100 (USA) FTIR spektrometre ile yapılmıştır. SEM görüntüleri JEOL JSM5500 LV model taramalı elektron mikroskobu ile elde edilmiştir. AFM ölçümleri ise Veeco di caliber atomik kuvvet mikroskobu ile yapılmıştır.

\section{Bulgular}

Bu çalışmada, bir Schiff bazı olan BAA kullanılarak farklı membranlar hazırlanmıştır. Hazırlanan destekli sıvı membranların kalınlıkları dijital bir mikrometre kullanılarak ölçülmüştür. Ölçümlerin ortalaması $(\mathrm{N}=10)$ alınarak membran kalınlığ $1 \mu \mathrm{m}$ olarak belirlenmiştir. Membranların kalınlık değerleri Tablo 2'de verilmiştir.

\begin{tabular}{lll}
\hline Membran & BAA-Poliamit & BAA- PVDF
\end{tabular}




\begin{tabular}{lll}
\hline Kalınlık $(\boldsymbol{\mu m})$ & $140 \pm 0.42$ & $120 \pm 0.54$
\end{tabular}

Kimyasal yapılarından dolayı katyon değiştirici özelliğe sahip bu membranlar kullanılarak sulu çözelti ortamından $\mathrm{Cu}(\mathrm{II})$ iyonlarının uzaklaştırılması donnan diyaliz yöntemi ile gerçekleştirilmiştir. Membrandan alıcı tarafa taşınan metal iyonlarının miktarı ICP-OES ile tayin

$J=\left(\frac{V}{A}\right)\left(\frac{d C^{n+}}{d t}\right)_{t \rightarrow 0}$

Buradaki V, alıcı çözeltinin hacmi, A, membranın etkin alanı ve $\mathrm{C}^{\mathrm{n}+}$ ise $\mathrm{t}$ zamanındaki iyon konsantrasyonudur. Destekli sıv1 membranlar ile yapılan edilmiş̧ir. Süreye karşılık taşınan metal iyonlarının mmol miktarları grafiğe geçirilmiştir. İyon akı hızı (J), alıcı taraftaki iyon konsantrasyonunun zamana karş1 çizilen grafiğin eğiminden bulunmuştur. İyon akı eşitliği aşağıdaki eşitlik ile ifade edilmiştir (Kimbrough vd., 1999).

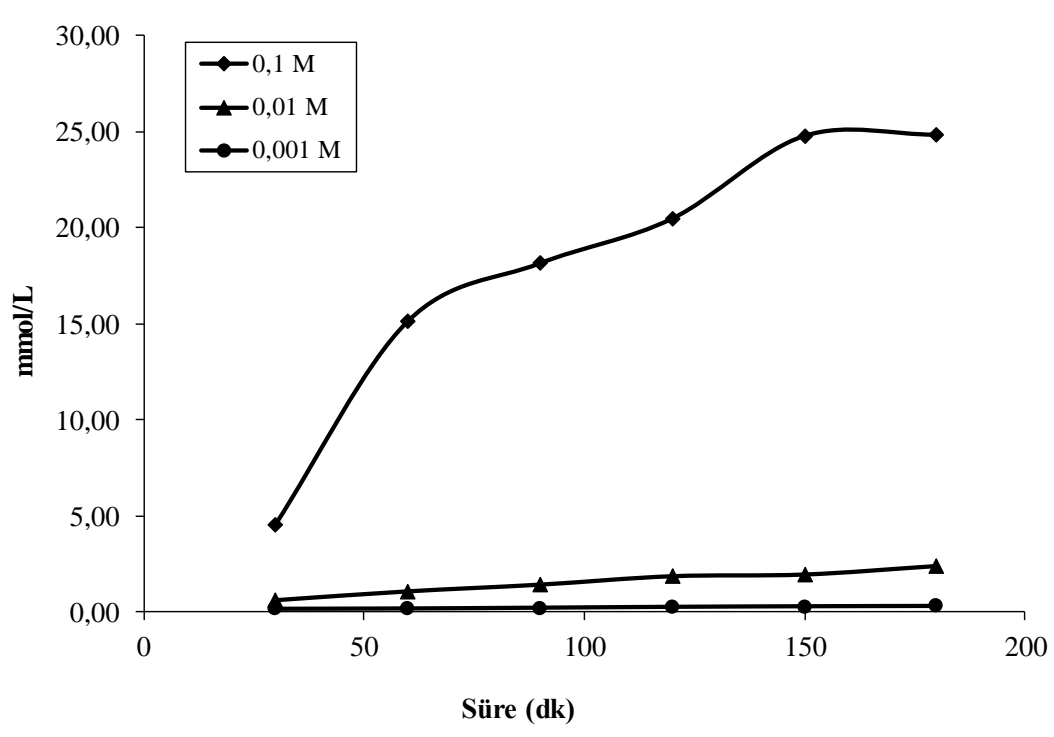

Şekil 2. BAA-Poliamit membranı için farklı besleme çözeltisi konsantrasyonlarında alıcı çözeltideki metal iyonlarının konsantrasyonunun zamana bağlı olarak değişimi 


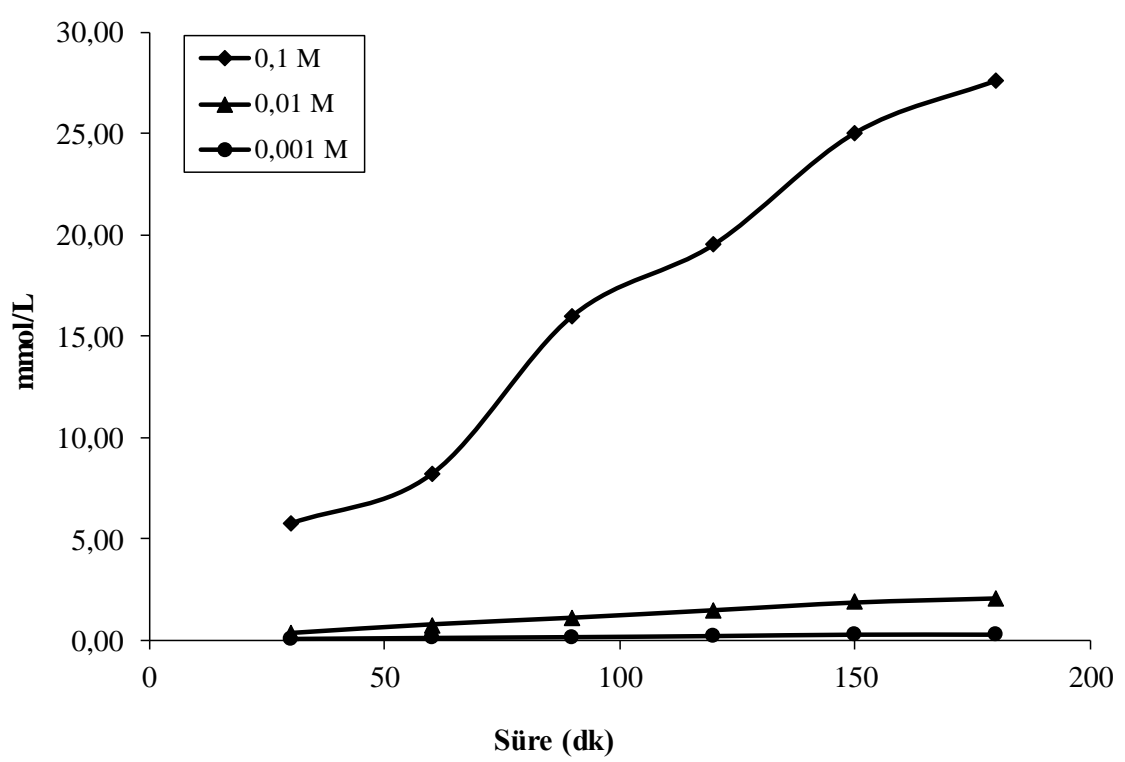

Şekil 3. BAA-PVDF membranı için farklı besleme çözeltisi konsantrasyonlarında alıcı çözeltideki metal iyonlarının konsantrasyonunun zamana bağlı olarak değişimi

Şekil 2 ve 3'te görüldüğ̈̈ gibi $\mathrm{Cu}(\mathrm{II})$ iyonlarının alıcı fazdaki taşınımı bakır konsantrasyonunun artışı ile artmıştır.
Hazırlanan destekli sıvı membranların akı değerleri (J) Tablo 3'de verilmiştir.

Tablo 3. Farklı yapıdaki membranlar için $\mathrm{Cu}(\mathrm{II})$ iyonlarının J değerleri

\begin{tabular}{|c|c|c|c|}
\hline Alıcı & Membranlar & Besleme & $\mathrm{Jx10}^{-10}\left(\mathrm{~mol} \mathrm{~cm}^{-2} \cdot \mathrm{s}^{-1}\right)$ \\
\hline \multirow{3}{*}{$1 \times 10^{-1} \mathrm{M}$} & \multirow{3}{*}{ BAA-Poliamit membran } & $1 \times 10^{-1} \mathrm{M} \mathrm{Cu}\left(\mathrm{NO}_{3}\right)_{2}$ & $128,00( \pm 3,360)$ \\
\hline & & $1 \times 10^{-2} \mathrm{M} \mathrm{Cu}\left(\mathrm{NO}_{3}\right)_{2}$ & $12,10( \pm 0,032)$ \\
\hline & & $1 \times 10^{-3} \mathrm{M} \mathrm{Cu}\left(\mathrm{NO}_{3}\right)_{2}$ & $1,18( \pm 0,003)$ \\
\hline \multirow{3}{*}{$1 \times 10^{-1} \mathrm{M}$} & \multirow{3}{*}{ BAA-PVDF membran } & $1 \times 10^{-1} \mathrm{M} \mathrm{Cu}\left(\mathrm{NO}_{3}\right)_{2}$ & $165,00( \pm 0,401)$ \\
\hline & & $1 \times 10^{-2} \mathrm{M} \mathrm{Cu}\left(\mathrm{NO}_{3}\right)_{2}$ & $12,70( \pm 0,011)$ \\
\hline & & $1 \times 10^{-3} \mathrm{M} \mathrm{Cu}\left(\mathrm{NO}_{3}\right)_{2}$ & $1,53( \pm 0,006)$ \\
\hline
\end{tabular}

Destekli sıvı membranların farklı çözücü ve destek tabakaları ile hazırlanması, bu membranların yapılarının da farklı olmasına yol açmıştır. Yapılardaki bu farklılık metallerin akı hızlarında da görülmektedir.
Membranların SEM görüntüleri JEOL 5600-LU model taramali elektron mikroskobu ile elde edilmiştir. Destekli sıvı membranların ve orijinal destek tabakalarının SEM fotoğrafları Şekil 4'te verilmiştir. 

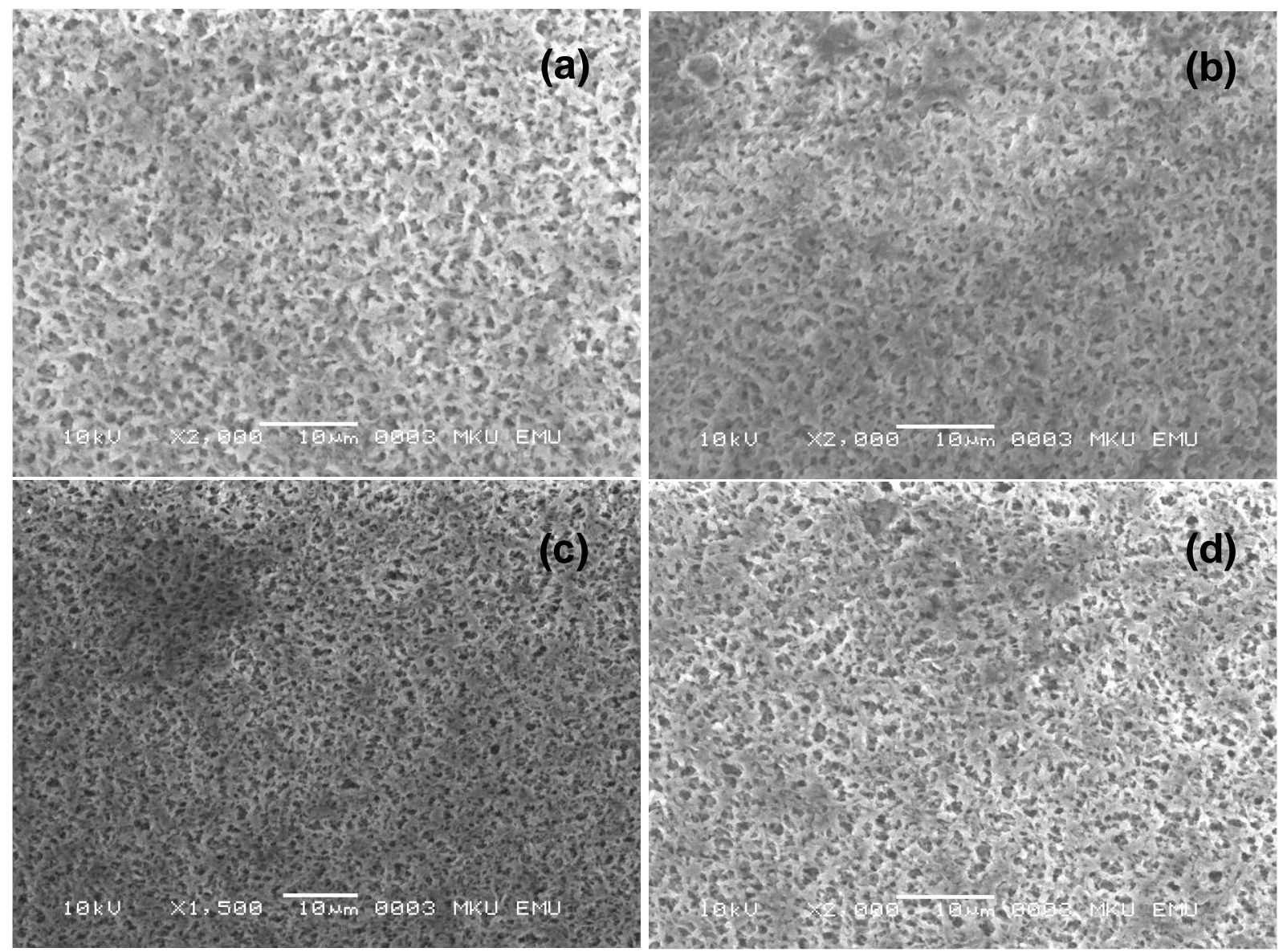

Şekil 4. Membranların SEM görüntüleri (a) BAA-Poliamit membran, (b) Orijinal Poliamit destek tabakası, (c) BAA-Hidrofob PVDF membran, (d) Orijinal Hidrofob PVDF destek tabakası

Yukarıdaki SEM görüntülerinden de görülebileceği gibi yeni hazırlanan membranların morfolojileri, orijinal ve taşıyıcı olmaksızın elde edilen membranlardan az da olsa farklilık göstermektedir. Fakat morfolojideki bu farklılık orijinal Poliamit destek tabakası ve BAA-Poliamit membranı arasında daha az gözlenmiştir. Poliamit membranın gözenek çapının $(0,45 \mu \mathrm{m})$ PVDF destek tabakasına
$(0,22 \mu \mathrm{m})$ göre daha büyük olması ve Poliamitin hidrofil karaktere sahip olması bu morfolojik değişimin daha az gözlenmesine yol açmış olabilir. Literatürde de benzer bir sonuç elde edilmiştir (Say vd., 2002). Destekli sıv1 membranların FTIR spektrumları ise orijinal destek tabakalarının FTIR spektrumları ile karşılaştırmalı olarak Şekil 5 ve Şekil 6'da sırasıyla verilmiştir. 




Şekil 5. BAA-Poliamit membranın (Kırmızı) ve Orijinal Poliamit destek tabakasının (Mavi) FTIR spektrumlar1

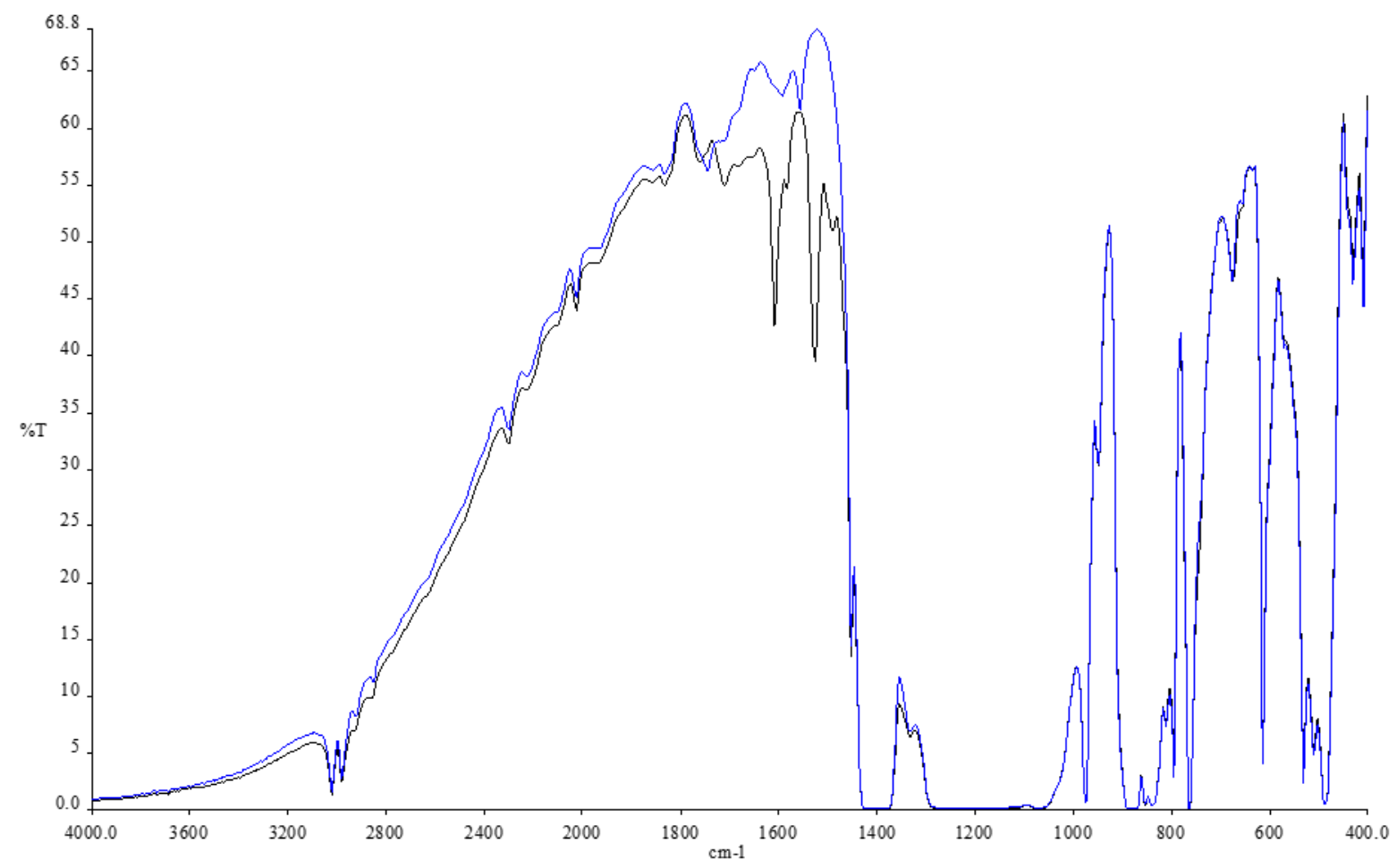

Şekil 6. BAA- PVDF membranın (Siyah) ve Orjinal Hidrofob PVDF destek tabakasının (Mavi) FTIR spektrumları 
Yukarıda verilen spektrumlarda, hazırlanan membranlara ait yeni titreşim bandları $\left(1600-1800 \mathrm{~cm}^{-1}\right)$ polimer destek tabakalarına BAA bileşiğinin bağlandığını göstermektedir. Bu yeni band BAA-PVDF için verilen spektrumda daha belirgin olarak ortaya çıkmışken BAA-Poliamit membranı için verilen spektrumda o kadar belirgin olarak izlenememiştir. Bu durum kullanılan poliamit destek tabakasının hidrofil özelliğinden kaynaklanmış olabilir. Hidrofil yapıya sahip olan destek tabakaları üzerlerine tutturulan taşıııcıyı daha çok yüzeyde bağlamak yerine iç kısımda bağlayabilir. Bu durum da morfolojide çok belirgin bir değişikliğe yol açmayabilir (Say vd., 2002).
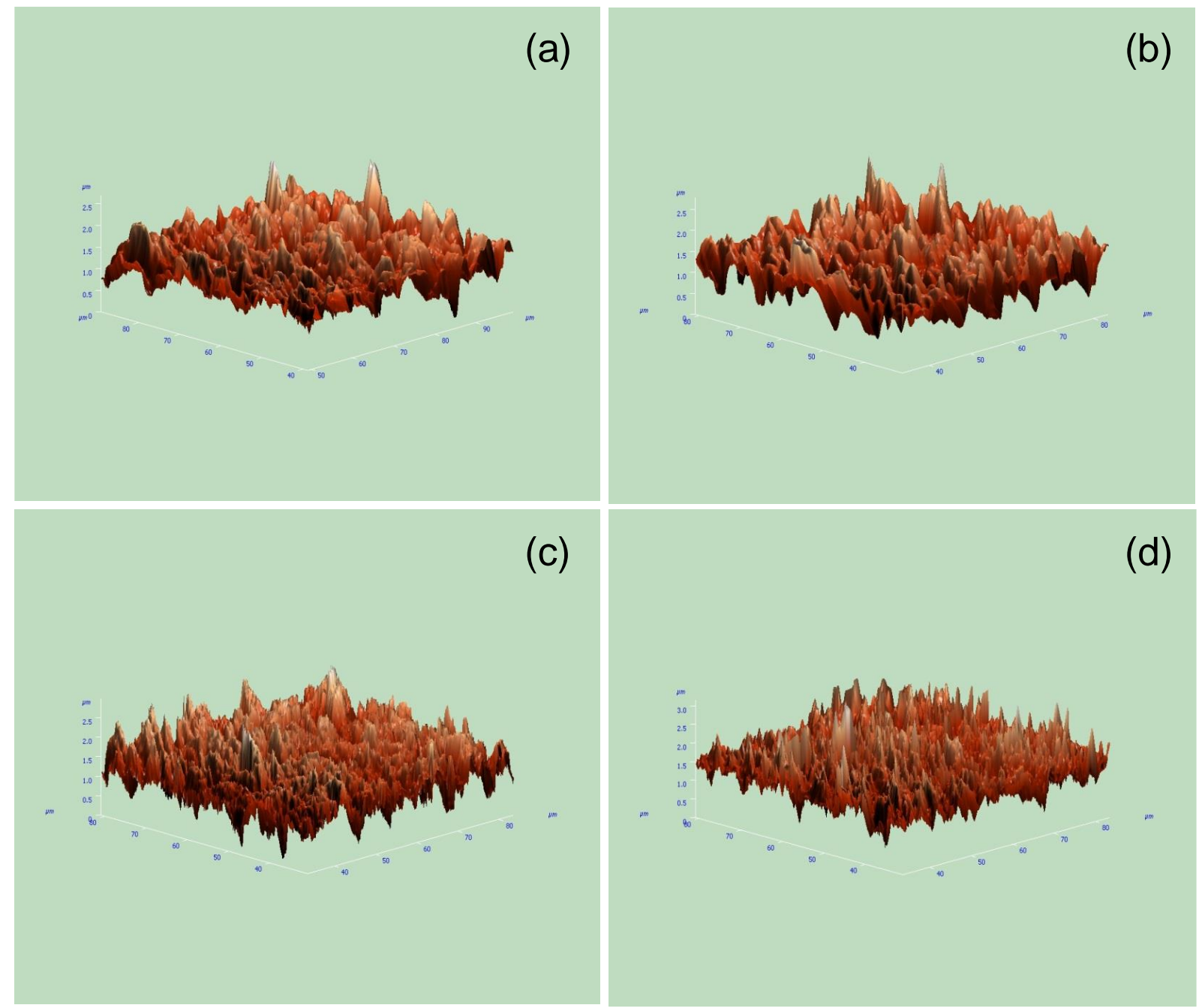

Şekil 7. Membranların AFM görüntüleri (a) Orijinal Poliamit destek tabakası, (b) BAAPoliamit membran, (c) Orijinal Hidrofob PVDF destek tabakası, (d) BAA-Hidrofob PVDF membran.

Hazırlanan membranların AFM görüntüleri de orijinal polimerlerden az da olsa farklıdır (Şekil 7). Bu durum hazırlanan destekli sıvı membranların yeni tür membranlar olduğunu göstermektedir. 
Membran potansiyellerinin ölçüm deneyleri, Em, Donnan diyaliz hücresinde yapılmıştır. Potansiyel ölçümleri, $\mathrm{Ag} / \mathrm{AgCl}$ elektrotlar (Mettler Toledo Inlab Reference Pro) ve bir elektrometre (Fluke 87 III True Rms Multimeter) kullanılarak gerçekleştirilmiştir. Düzenekte orta kısma membranlar yerleştirilmiştir. 1 . ve 2 . bölmelere pH 3-8 arasındaki tuz çözeltileri yerleştirilmiştir. Tuz çözeltilerinin konsantrasyonları sabit tutulmuştur. Birinci bölümde, $\mathrm{C}_{1}, 2,0.10^{-4} \mathrm{~mol} / \mathrm{L} \mathrm{NaCl}$, ikinci bölümde, ise $\mathrm{C}_{2}, 1,0.10^{-4} \mathrm{~mol} / \mathrm{L} \mathrm{NaCl}$ çözeltisi bulunmaktadır. İki bölme arasındaki konsantrasyon oran1 2 olarak sabit tutulmuştur.
Hücrenin elektriksel potansiyel farkı ( $E_{\text {cell }}$, her iki bölümdeki elektrotların alışverişi ile elde edilmiş iki ölçümün aritmetik ortalama değeri ile elde edilmiştir. Membran potansiyeli, Em, $\mathrm{E}_{\text {cell }}$ ve $\mathrm{E}_{\mathrm{c}}$ arasındaki fark olarak ifade edilmektedir.

$$
E_{m}=E_{\text {cell }}-E_{c}
$$

$E_{c}$ konsantrsayon potansiyeli olarak belirtilmiştir (Szymczyk vd., 1998).

$$
E_{c}=-\frac{R T}{F} \ln \frac{a_{2}}{a_{1}}
$$

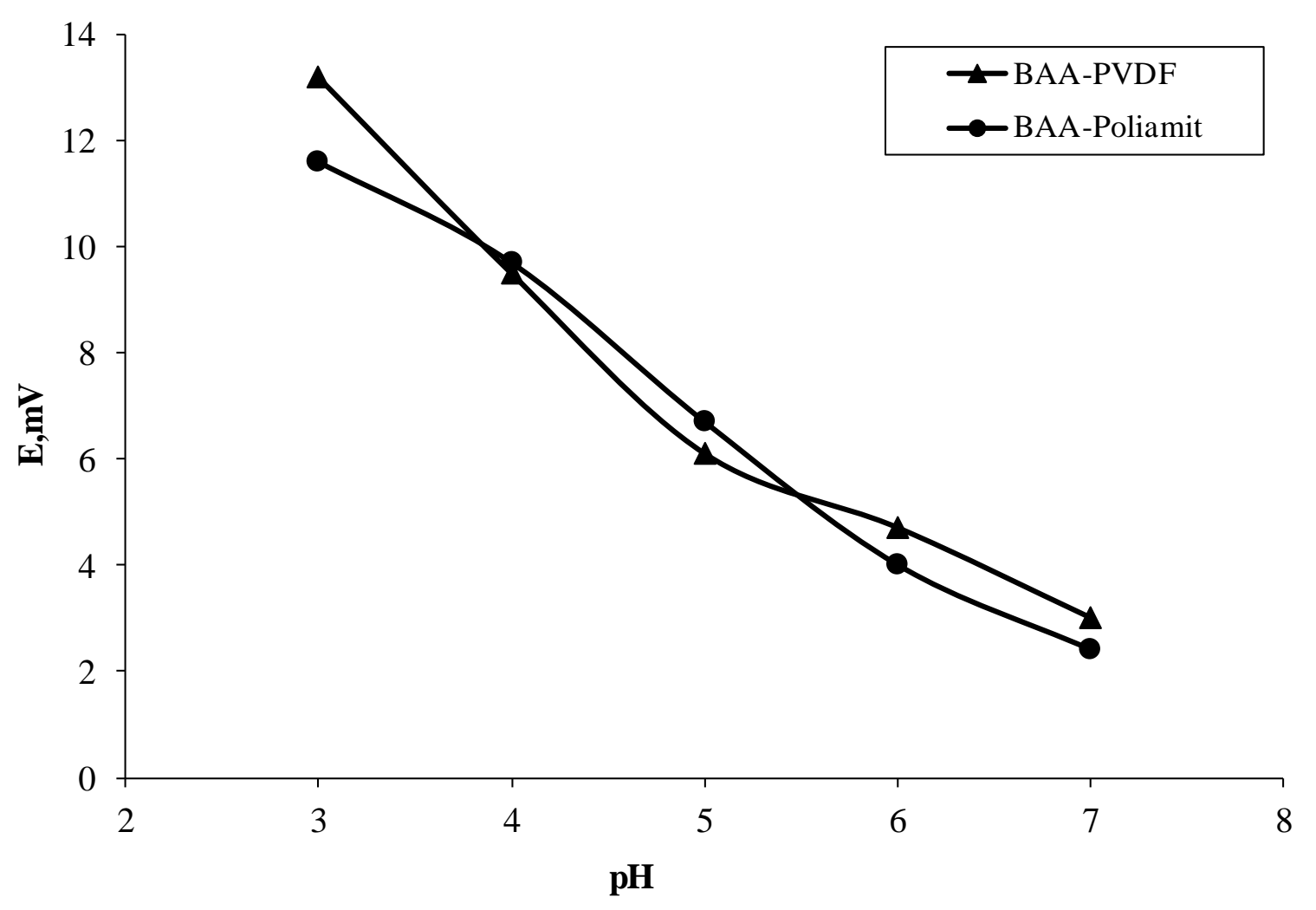

Şekil 8. Farklı membranlar için membran potansiyelinin pH'ya bağlı olarak değişimi

Şekil 8'de, $2.10^{-4} \mathrm{~mol} / \mathrm{L}$ ve $1.10^{-4} \mathrm{~mol} / \mathrm{L}$ $\mathrm{NaCl}$ çözeltileri için membran potansiyelinin $\mathrm{pH}$ ile değişimi görülmektedir. Şekilden de görüldüğü gibi membran potansiyel değerleri bütün membranlar için kıyaslandığında önemli bir 
fark göstermemiştir. Membran potansiyel değerleri, membran yükü negatif olmaya başladığı için, bütün membranlarda $\mathrm{pH}$ artışı ile azalmıştır. Membranlar $\mathrm{NaCl}$ içinde negatif yüklenmektedir (Szymczyk vd., 1998).

\section{Sonuç ve Tartışma}

$\mathrm{Bu}$ çalışmada, donnan diyaliz yöntemi ile DSM'lar kullanarak sulu çözeltiden $\mathrm{Cu}(\mathrm{II})$ iyonunun uzaklaştırılması amaçlanmıştır. Her bir membran için alıcı tarafa taşınan $\mathrm{Cu}$ (II) iyonu konsantrasyonlarından akı hızı değerleri ve \% geri kazanım değerleri hesaplanmış ve gerekli grafikler çizilmiştir. Çizilen grafiklerden ve elde edilen akı değerlerinden hareketle:

Besleme çözeltisinde farklı konsantrasyonlarda yapilan deneylerde, konsantrasyon artışının $\mathrm{Cu}(\mathrm{II})$ iyonu akısını artırdığı tespit edilmiştir. Bu durum elde edilen akı değerlerinden de görülmektedir.

BAA-Poliamit ve BAA-PVDF DSM'ların $\mathrm{Cu}$ (II) iyonu giderimi açısından kıyaslandığında, BAA-Poliamit DSM'nin daha fazla $\mathrm{Cu}(\mathrm{II})$ iyonunu uzaklaştırdığı gözlenmiştir. Membran yapılarının farklılığının bu duruma yol açtığı düşünülmektedir. Hazırlanan membranların morfolojik özellikleri de SEM, AFM ve FTIR ile incelenmiştir.

\section{Teşekkür}

$\mathrm{Bu}$ çalışma TUBİTAK 2209-Üniversite Ögrencileri Yurt İçi/Yurt Dışı Araştırma Projeleri Destekleme Programı tarafindan desteklenmiştir.

\section{Kaynaklar}

Cengeloglu, Y., Kir, E. Ersoz, M. 2001. "Recovery and Concentration of $\mathrm{Al}$ (III),
$\mathrm{Fe}(\mathrm{III}), \mathrm{Ti}(\mathrm{IV})$, and $\mathrm{Na}(\mathrm{I})$ from Red Mud", Journal of Colloid and Interface Science, 244 (2), 342-346.

Gherrou, A., Kerdjoudj, H., Molinari, R., Drioli, E. 2002. "Removal of silver and copper ions from acidic thiourea solutions with a supported liquid membrane containing D2EHPA as carrier", Separation Purification and Technology, 28, 235-244.

Kimbrough, D.E., Cohen, Y., Winer, A.M., Creelman, L., Mabuni, C.A. 1999. “A critical assessment of chromium in the environment", Critical Reviews in Environmental Science and Technology, 29 (1), 1-46.

Ndungu, K., Hurst, M.P., W. Bruland, K. 2005. "Comparison of copper speciation in estuarine water measured using analytical voltammetry and supported liquid membrane techniques", Environmental Science \& Technology, 39, 3166-3175.

Parhi, P.K., Sarangi, K. 2008. "Separation of copper, zinc, cobalt and nickel ions by supported liquid membrane technique using LIX 84I, TOPS-99 and Cyanex 272", Separation Purification and Technology, 59, 169-174.

Romero, R., Jönsson, J.A. 2005. "Determination of free copper concentrations in natural waters by using supported liquid membrane extraction under equilibrium conditions", Analytical and Bioanalytical Chemistry, 381, 14521459.

Say, R., Senel, S., Denizli, A. 2002. "Preparation of Cibacron BlueF3GAAttached Polyamide Hollow Fibers for Heavy Metal Removal", Journal of Applied Polymer Science, 83(14), 3089-3098. 
Shauib, N.M., Elassar, A.Z.A., ElDissouky, A. 2006. "Synthesis and spectroscopic characterization of copper(II) complexes with the polydentate chelating ligand 4,4-[1,4-phenylenedi(nitrilo) dipente-2-one", Spectrochimica Acta Part A: Molecular and Biomolecular Spectroscopy, 63, 714-722.

Silva, R.F., De Francesco, M., Pozio, A. 2004. "Solution-cast Nafion ${ }^{\circledR}$ ionomer membranes: preparation and characterization", Electrochimica Acta, 49 (19), 3211-3219.

Szymczyk, A., Fievet, P., Reggiani, J.C., Pagetti, J. 1998. "Characterisation of surface properties of ceramic membranes by streaming and membrane potentials", The Journal of Membrane Science, 146, 277-284.

Takahashi, K., Takeuchi, H. 1985. "Transport of copper through a supported liquid membrane", Journal of Chemical Engineering of Japan, 18 (3), 205-211.

Wodzki, R., Sionkowski, G., Poźniak, G. 1999. "Recovery and concentration of metal ions. IV. Uphill transport of Zn (II) in a multimembrane hybrid system", Separation Science and Technology, 34 (4), 627-649.

Yang, X.J., Fane, A.G. 1999. “Performance and stability of supported liquid membranes using LIX 984N for copper transport", Journal of Membrane Science, 156, 251263. 